University of Navarra

\title{
ARE ANOMALIES STILL ANOMALOUS? AN EXAMINATION OF MOMENTUM STRATEGIES IN FOUR FINANCIAL MARKETS
}

Daxue Wang 


\title{
ARE ANOMALIES STILL ANOMALOUS? AN EXAMINATION OF MOMENTUM STRATEGIES IN FOUR FINANCIAL MARKETS
}

\author{
Daxue Wang ${ }^{1}$
}

\begin{abstract}
In this paper we test the profitability of momentum strategies in the United Kingdom, Germany, Japan, and China over the period 1991 to 2006 and sub-periods. Both RSS (Relative Strength Strategies) and WRSS (Weighted Relative Strength Strategies) are used to form the momentum portfolios. As a result, we find that the United Kingdom and Germany exhibit rather stable medium-term return continuation for both RSS and WRSS over the entire sample period and sub-periods, while Japan shows a medium-term return reversal over the sub-period 1991-1998. As for China, we report momentum profits over the period 1995-2006 and the sub-period 20012006 with RSS. Furthermore, we use the results of RSS to check the influence of risk factors and transaction costs on the momentum returns, as well as calendar effects and other characteristics of momentum portfolios reported in the literature. With the results of WRSS, we examine the relative importance of time-series predictability and cross-sectional variation in accounting for the profits of momentum strategies.
\end{abstract}

JEL Classification: G11, 141, G15

Keywords: Momentum Strategy, Time-Series Predictable Components, Cross-Sectional Variation

${ }^{1} \mathrm{PhD}$ in Finance at IESE 


\section{ARE ANOMALIES STILL ANOMALOUS? AN EXAMINATION OF MOMENTUM STRATEGIES IN FOUR FINANCIAL MARKETS}

\section{Introduction}

The concept of Efficient Market Hypothesis (EMH) appeared in 1960s and reached such a height of dominance around 1970s that any deviation in financial markets has been called anomaly. The 1980s has witnessed the proliferation of reported anomalies. For example, the cross-section of equity returns has been reported as predictable based on past returns over various horizons. Among them, medium-term continuation of equity returns, also called "momentum strategy", is the most intriguing phenomenon. It has not been traded away, despite being well known as public information for years.

Jegadeesh and Titman $(1993,1995)$ are the first to report medium-term profit "momentum". Upon examining a variety of momentum strategies in the United States stock market over the sample period 1965 to 1989, they find that strategies that buy winning stocks (stocks with high returns over the previous three months to one year) and sell losing stocks (stocks with low returns over the same period) earn profits of about 1 percent per month for the following year. They propose that underreaction of stock prices to information contained in past stock returns leads to this profit momentum.

Since their very first appearance as an anomaly to the EMH, momentum strategies have been criticized by many as the product of a data snooping process. However, when Jegadeesh and Titman (2001) extend the original sample period to the period of 1990 to 1998, profits about the same magnitude as in their earlier paper are once again documented. Grundy and Martin (2001) further extend the sample period and document that momentum profits are remarkably stable across sub-periods post 1926. Besides, other researchers have checked stock markets of different regions over different time periods using various methods, and have consistently reported positive returns by implementing these strategies. For instance, momentum profits of a similar size to that of the United States market are documented in several European markets by Rouwenhorst (1998) and in Asian markets (Japan and Korea as exceptions) by Chui et al. (2000). In practice, momentum strategies are also favored by many practitioners in their investment activities. Grinblatt et al. (1995) find that about 77 percent of mutual funds in their sample use momentum strategies in their investment. 
The proponents of EMH argue that the winner-loser results can be accounted within the framework of risk factor models. Zarowin (1990) attributes them to the size factor effect: Small stocks, often losers, have higher expected return than large stocks. Chan et al. (1996) show that medium-term performance continuation can be partly explained by underreaction to earnings information, but price momentum is not subsumed by earnings momentum. Fama and French (1996) try to account for the cross-section stock return predictability with their multifactor model. However, they find that long-term reversals can be consistent with the model, but fail to explain medium-term return continuation. Chopra et al. (1992) show that losers would have to have much higher betas than winners in order to justify the return differences, and the beta in the CAPM framework cannot account for it. Grundy and Martin (2001) find that neither industry effects nor cross-sectional differences in expected returns are the primary cause of the momentum phenomenon, and the strategy's average profitability cannot be explained by Fama and French's three-factor model.

Some behavioral models have been provided to explain the momentum strategy. Grinblatt and Han (2001) argue that the disposition effect accounts for a large percentage of the momentum in stock returns. The concavity (convexity) of the value function in the gains (losses) region makes investors willing to sell (hold) a stock which has earned them capital gains (losses). And this may initially depress (inflate) the stock price, generating higher (lower) returns later. Hirshleifer and Shumway (2003) attribute the momentum to the fact that low returns on a stock put the investors of the stock in a negative, critical mood. This bad mood may in turn cause skeptical and pessimistic interpretation of subsequently arriving information. People will not fully foresee their negative interpretation of future information, causing a tendency toward continuation of the drop in price. Other behavioral models include Barberis et al. (1998), Daniel et al. (1998), and Hong and Stein (1999), which we will introduce in detail in Section I of this paper.

In this paper, we examine momentum strategies in four major financial markets in Europe and Asia: the United Kingdom, Germany, Japan, and China. The choice of these markets for this study is motivated by the fact that they are among the most important equity markets in the world, ranking top two in their respective continents. Besides, the sample includes an emerging market, China. In his response to the critiques of the EMH, Fama (1998) argues that the return anomalies should stand up to out-of-sample tests. If the conclusions derived from developed markets are robust, we should find a similar effect in emerging markets. Since China's stock market is usually considered to be independent of its United States counterpart, findings of a similar pattern from independent samples help to relieve the concern of data snooping.

The purposes of the paper are five-fold. Firstly, we test the profitability of momentum strategies of different investment horizons in an international setting. If the return continuation is absent in international markets, this suggests that the United States experience may simply have been an exception rather than the rule. We use a comprehensive sample including nearly all listed stocks in each market, avoiding the "larger firms" bias in Rouwenhorst (1998). By doing so, we can also check the validity of various explanations provided in the literature. Secondly, we compare the consistency of the results under different portfolio formation frameworks. In building relative strength strategies, the momentum literature can be divided into two streams: RSS (Relative Strength Strategies), proposed by DeBondt and Thaler (1985) and Jegadeesh and Titman (1993), and WRSS (Weighted Relative Strength Strategies), proposed by Lo and MacKinlay (1990) and Conrad and Kaul (1998). In this paper, we calculate the profits of trading strategies in both methods and then check the consistency. To our knowledge, this paper is the first to do so. 
Thirdly, the paper checks whether the momentum profits are significant after taking risk factors and transaction costs into account. Fourthly, we examine whether the characteristics of momentum profits reported in the literature, such as calendar effect, apply to the sample markets. And fifthly, we evaluate the relative importance of difference sources of the profitability, if any, to trading strategies. Using the framework of Conrad and Kaul (1998), we decompose the profits of momentum strategies into two parts: one that results from the timeseries predictability in security returns, and the other from the cross-sectional variation in the mean returns of the securities comprising the portfolio. It is important to determine the sources of profits from the trading strategies, since only the first part is associated with the return predictability, and in turn, the anomalous effect.

We find that the results obtained with RSS and WRSS have relatively high correlations. Under both methods, Winners outperform Losers in the medium-term horizons for nearly all holding periods in the United Kingdom and Germany, and for most of the periods in China. The outperformance lasts for about two years. In Japan, we document negative average returns for the momentum portfolios over nearly all holding periods. Further tests show that the momentum returns cannot be explained by the Fama-French three-factor model. Similar to the United States markets, the cumulative momentum profits turn negative for horizons of longer than two years. ${ }^{1}$ Different from the United States markets, we do not observe the January effect in the sample markets. The concavity of the cumulative momentum profits over various holding periods shows that the behavioral models are supported. Besides, we check the correlation among the sample markets and document a significant correlation between the United Kingdom and Germany. Furthermore, transaction costs do not rule out the profitability of the momentum strategies for a majority of the holding periods.

Contrary to Conrad and Kaul (1998) who report a negligible role of the time-series predictable components in the United States market, we find that the expected profits are highly predictable for most of the trading strategies from the time-series components for all the sample markets. Besides, the cross-sectional variance of mean returns of individual securities increases with the trading horizon, but the magnitude of the increase is much smaller than the random walk hypothesis predicts.

The remainder of the paper is organized as follows. Section I develops the hypotheses of this paper based on several models aiming to explain the momentum profits. Section II describes the data and our methodology, together with empirical findings of the RSS and WRSS. Section III examines whether the profits can be explained by the F-F three-factor model and transaction costs, as well as some reported characteristics of the momentum returns. Section IV decomposes the profit sources and compares the relative importance of each component. Section V concludes the paper with a brief summary and suggestions for future research.

\section{The Hypotheses}

Barberis et al. (1998), Daniel et al. (1998), and Hong and Stein (1999) propose behavioral models to explain the momentum phenomenon and long-term return reversal documented by DeBondt and Thaler $(1985,1987)$. These behavioral models imply that the holding period abnormal returns arise because of a delayed overreaction to information that pushes the prices of winners (losers) above (below) their long-term values. The misperceptions that drive

\footnotetext{
${ }^{1}$ In the United States, the momentum profits turn negative in one year, as reported by Jegadeesh and Titman (2001).
} 
momentum are also the drivers of long-term reversals. Thus, if there is some market segmentation, then those sets of assets with largest momentum effects should also have the largest reversals.

Barberis et al. (1998) combine the conservatism bias with representative heuristics to explain the long-term overreaction and the shorter-term momentum. The authors argue that the representativeness may lead investors to mistakenly conclude that firms realizing extraordinary earnings growths will continue to do so in the future. Although the conservatism bias alone leads to underreaction, the joint effect of conservatism of representativeness can lead to longhorizon negative returns for stocks with consistently high past returns. By examining predictions of MBA students as experimental subjects, Bloomfield and Hales (2001) test Barberis et al. (1998) theory that people misperceive random walks to be shifts between continuation and reversals regimes. And it is confirmed that subjects overreacted to changes preceded by sequences of continuations, and underreacted to changes preceded by many reversals.

Daniel et al. (1998) believe that investors suffer from a self-attribution bias: Investors tend to attribute the performance of ex post winners to their stock selection skills and that of ex post losers to bad luck. After the investment result is revealed, these investors become overconfident about their ability to pick winners and over-estimate the precision of their signals that had been confirmed by prior outcomes. Based on their increased confidence in their signals, they push up the prices of the winner above the fundamental values. On the other hand, the delayed overreaction in their model leads to momentum profits that are eventually reversed as prices revert to the fundamental values.

Hong and Stein (1999) adopt a different approach from Daniel et al. (1998) and Barberis et al. (1998). Rather than trying to say much about the psychology of the representative agent, they emphasize the interaction between two groups of bounded rational agents: "newswatchers" and "momentum traders". Newswatchers make forecasts based on signals that they privately observe about future fundamentals; however, they do not condition on current or past prices. Momentum traders do condition on past price changes; however, their forecasts are simply made on the history of past prices. These authors also assume that private information diffuses gradually across the newswacher population. Thus, initially, when only newswatchers are active, prices adjust slowly to new information, leading to underreaction. Later on, momentum traders intervene and arbitrage away any underreaction left behind by the newswatchers. But with the simple arbitrage strategy, they only partially eliminate the underreaction and, in doing so, create an excessive momentum in prices that culminates in overreaction. In other words, the very existence of underreaction sows the seeds for overreaction. In this process, early momentum buyers impose a negative externality on late momentum buyers.

Based on these behavioral models, we build our first hypothesis as follows:

H1: The momentum strategies earn positive returns over the medium-term holding period, but in the long-term the positive returns will be reversed and turn negative.

Based on Lo and MacKinlay (1990), Conrad and Kaul (1998) argue that the momentum profits documented in the United States are not necessarily caused by the time-series predictable component, but could be due to cross-sectional variation in the mean returns of individual stocks. In other words, the evidence of momentum strategies is not enough to argue against the EMH. They start with the hypothesis that stock prices follow random walks plus drifts, and the unconditional drifts vary across stocks. With their sample, they show that the profitability of 
momentum strategies is due to the cross-sectional variation, and the time-series predictability is negligible. With these arguments, we build our second hypothesis as follows:

H2: Upon decomposition, the time-series predictable components of the momentum returns are non-significant and account for only a small percentage of the total expected momentum returns.

\section{Data \& Methodology}

\subsection{Data}

Monthly adjusted prices (in local currencies) of stocks listed in stock exchanges of the United Kingdom, Germany, and Japan and China are obtained from Datastream, covering the period 1990 (1994 for China) to 2006. The sample consists of a total of 8,898 stocks: the United Kingdom $(2,133)$, Germany $(1,242)$, Japan $(3,929)$, and China $(1,594)$. These stocks cover more than 95 percent of each country's market capitalization. With these data, we calculate profits of various momentum strategies from January 1991 (January 1995 for China) to December 2006.

Several filters are used in calculating profits of the equities: First, the price of the first month for each stock is deleted to eliminate the effect of IPO (Initial Public Offerings) underpricing. Second, stocks with a history of less than three years are ruled out. With these filters the remaining sample consists of 1,979 stocks in the United Kingdom, 1,088 stocks in Germany, 3,837 stocks in Japan, and 1,584 stocks in China.

Later in the paper, we will check whether Fama-French three-factor model can account for the profits of momentum strategies. In doing so, we use Morgan Stanley Country Index (MSCI) as the proxy of market, which covers above 85 percent of the total market capitalization of each country. To calculate the excess market return, we approximate the risk-free rate of return with short-term treasury bill rate or time deposit (when treasury bill rate is not available), which is obtained from Global Financial Market Database.

Table 1 lists the descriptive statistics of the above-mentioned variables. During the sample period, the monthly average return on the market index ranges between -0.06 percent (Japan) and 0.68 percent (Germany); the average short-term interest rate ranges between 0.12 percent (Japan) and 0.51 percent (the United Kingdom). Table 1 also reports the SMB and HML factors of Fama-French for the sample markets. To calculate these factor values, we follow the method described in Fama and French (1993) to form the 6 size-BE/ME stock portfolios based on all the equities in Datastream.

\subsection{Profits of Relative Strength Strategy (RSS):}

First, we form the relative strength portfolios as described in Jegadeesh and Titman (1993). At the end of each month $t$, all stocks are ranked in ascending order on the basis of their past $J$ months' returns $(J=3,6,9$, or 12). Based on these rankings, the stocks are assigned to one of ten decile portfolios. The top decile portfolio is called the "Loser", while the bottom decile is called the "Winner". These portfolios are equally weighted at formation, and held for $K$ subsequent months $(K=3,6,9$, or 12$)$. 


\section{Table 1}

Descriptive Statistics of Equities in the Sample Markets

This table lists the descriptive statistics of the market index, short-term interest rate, and FamaFrench factors for the sample markets over the sample period. To calculate these factor values, we follow the method described in Fama and French (1993) to form the 6 size-BE/ME stock portfolios based on all the equities in Datastream.

\begin{tabular}{|c|c|c|c|c|c|}
\hline & & United Kingdom & Germany & Japan & China \\
\hline \multicolumn{2}{|c|}{ Time Period } & $\begin{array}{c}\text { Jan-91 to } \\
\text { Dec-06 }\end{array}$ & $\begin{array}{l}\text { Jan-91 to } \\
\text { Dec-06 }\end{array}$ & $\begin{array}{l}\text { Jan-91 to } \\
\text { Dec-06 }\end{array}$ & $\begin{array}{l}\text { Jan-95 to } \\
\text { Dec-06 }\end{array}$ \\
\hline \multicolumn{2}{|c|}{ Number of Stocks } & 1971 & 1088 & 3837 & 1584 \\
\hline \multirow{2}{*}{$\begin{array}{l}\text { Return } \\
\text { on MSCI }\end{array}$} & Mean & 0.0055 & 0.0068 & -0.0006 & 0.0037 \\
\hline & Std. Dev. & 0.0404 & 0.0619 & 0.0569 & 0.1096 \\
\hline \multirow{3}{*}{$\begin{array}{l}\text { Risk-Free } \\
\text { Interest } \\
\text { Rate }\end{array}$} & Type & 3 month T-bill & 3 month T-bill & 3 month T-bill & Time Deposit \\
\hline & Mean & 0.0051 & 0.0035 & 0.0012 & 0.0034 \\
\hline & Std. Dev. & 0.0021 & 0.0621 & 0.0019 & 0.0024 \\
\hline \multirow{2}{*}{$\mathrm{R}_{\mathrm{m}}-\mathrm{R}_{\mathrm{b}}$} & Mean & 0.0004 & 0.0033 & -0.0018 & 0.0003 \\
\hline & Std. Dev. & 0.0405 & 0.0621 & 0.0572 & 0.1098 \\
\hline \multirow{2}{*}{$\mathrm{R}_{\mathrm{SMB}}$} & Mean & 0.0194 & 0.0119 & 0.0058 & 0.0005 \\
\hline & Std. Dev. & 0.0561 & 0.0523 & 0.0424 & 0.0618 \\
\hline \multirow{2}{*}{$\mathrm{R}_{\mathrm{HML}}$} & Mean & 0.0018 & 0.0062 & 0.0007 & 0.0162 \\
\hline & Std. Dev. & 0.0325 & 0.0606 & 0.0345 & 0.117 \\
\hline
\end{tabular}

To minimize small-sample biases and to increase the power of the test, we implement trading strategies for overlapping holding periods on a monthly frequency. Therefore, in any given month $t$, the strategies hold a series of portfolios that are selected in the current month as well as in the previous $K-1$ months. This is equivalent to a composite portfolio in which $1 / K$ of the holding is replaced each month. To avoid the potential "survival biases", we do not require all securities included in a particular strategy in the formation period to survive up to the end of the holding period. If a security $i$ survives for less than $J$ periods, we use a $(J-j)$ period return in calculating $R_{i, t}(J)$, where $j$ is the period of delisting. If a security does not survive the formation period, it is dropped from the particular strategy. 


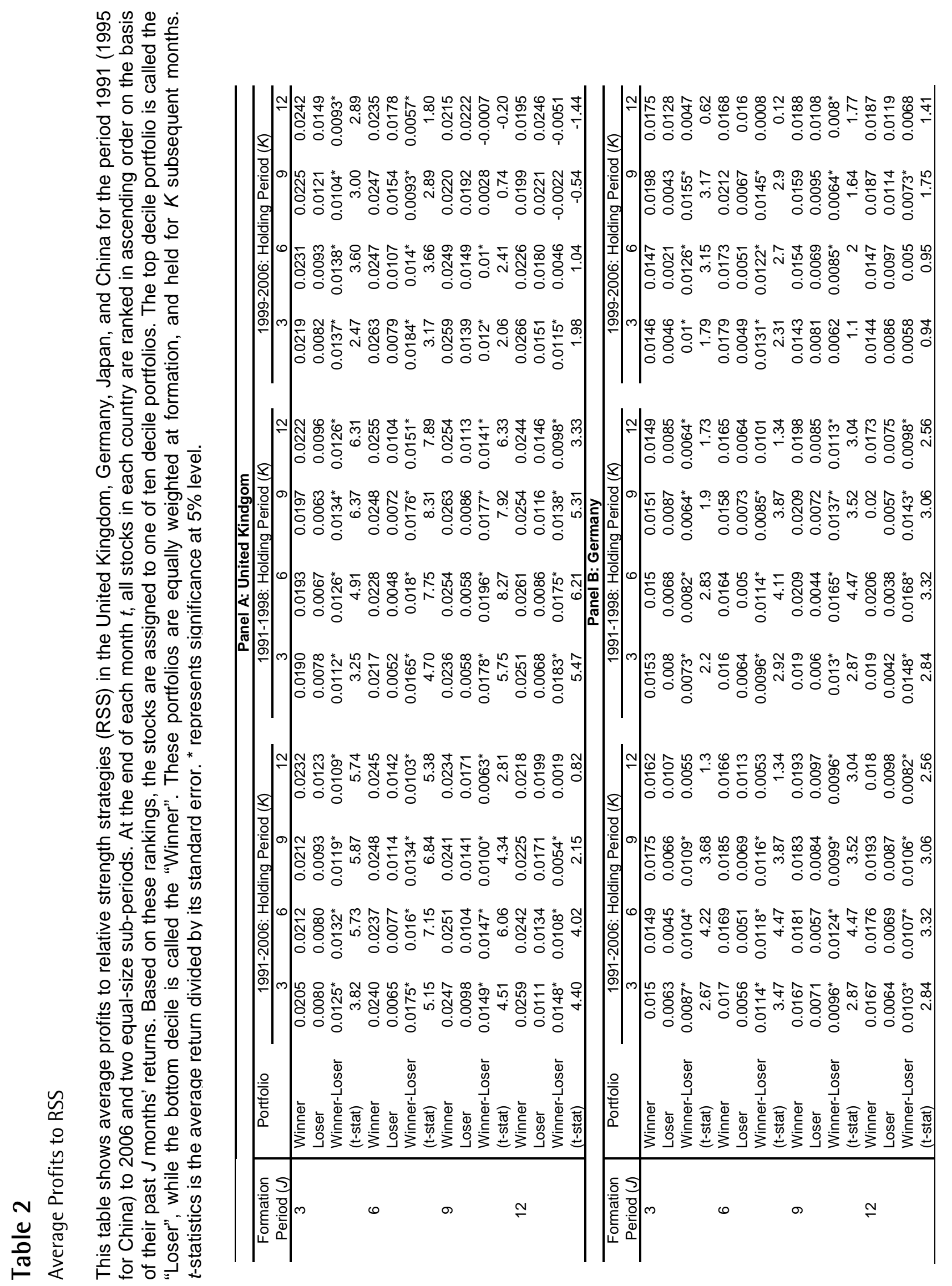




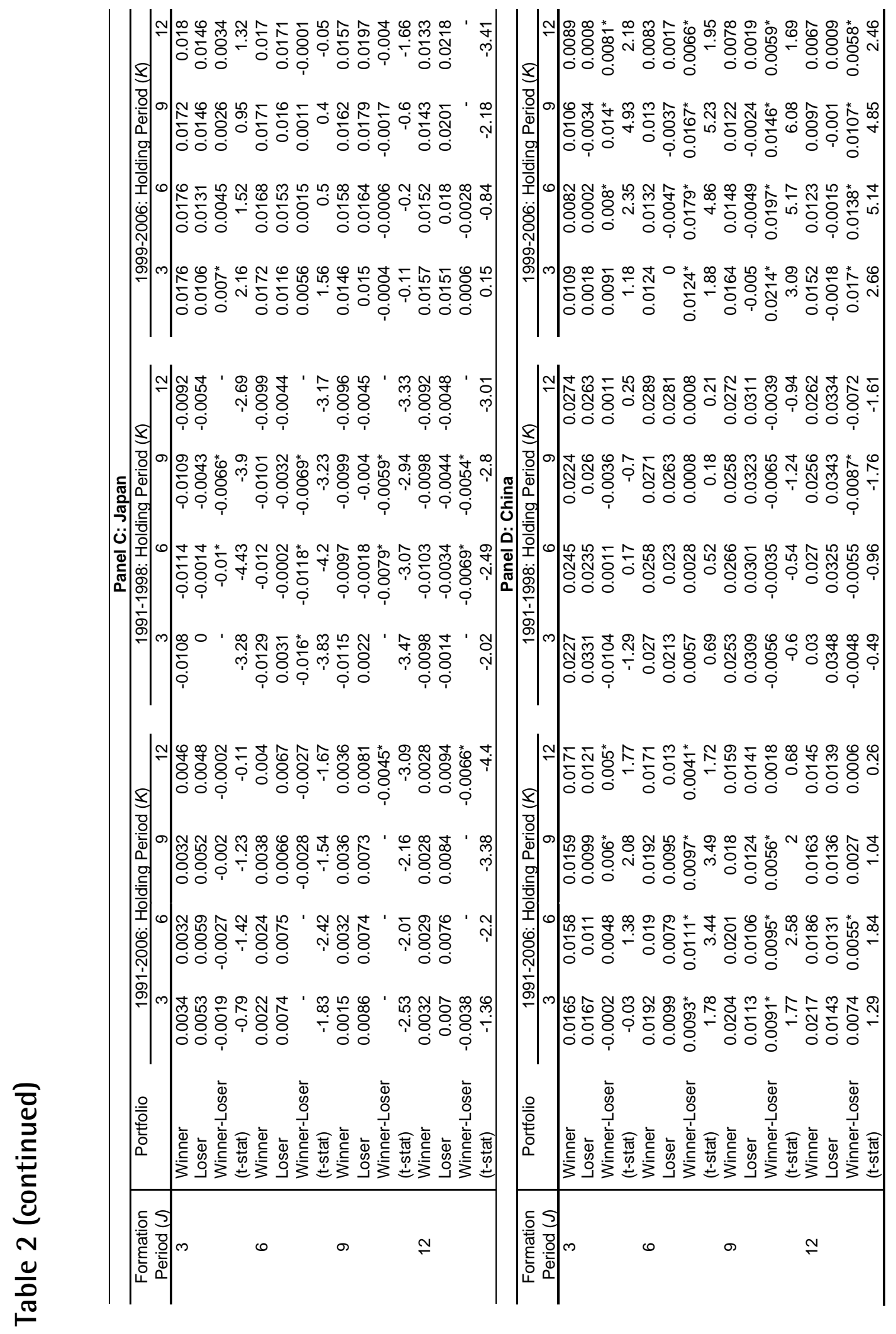


Table 2 shows the average monthly buy-and-hold returns on the composite portfolio strategies implemented during different periods in each country, with Panel A, B, C, and D presenting the results for the United Kingdom, Germany, Japan, and China, respectively. For the United Kingdom, Germany, and Japan, we consider the period 1991 to 2006 and two equal-size subperiods. For China, we consider the period 1995 to 1996 and two equal-size sub-periods. ${ }^{2}$

For each strategy, the table lists the returns of the "Winner" and the "Loser", as well as the excess returns (and $t$-stat) from buying "Winner" and selling "Loser". For instance, as Panel A shows, during the period 1991-2006 buying "Winner" from a 3-month/3-month strategy in the United Kingdom earns an average return of 2.05 percent per month, 1.25 percent higher than buying "Loser" in the same strategy, which returns 0.90 percent. The excess return is significant at the 5 percent level of significance, with a $t$-stat of 3.82 .

For the entire period 1991-2006, among the sixteen strategies in each market, significantly positive excess returns are observed at the 5 percent level for fifteen strategies in the United Kingdom, fourteen in Germany, zero in Japan, and ten in China. For the same period, significantly negative excess returns at the 5 percent level are only seen for nine strategies in Japan. Specifically, the excess returns of buying "Winner" over buying "Loser" range from 0.19 to 1.75 percent per month in the United Kingdom (with a mean of 1.15 percent), from 0.53 to 1.24 percent in Germany (with a mean of 0.98 percent), from -0.71 to -0.02 percent in Japan (with a mean of -0.39 percent), and from -0.02 to 1.11 percent in China (with a mean of 0.58 percent).

For the United Kingdom and Germany, the portfolio returns of both sub-periods are at a comparable scale to those of the entire sample period, with a majority of the strategies earning significant positive returns. In the United Kingdom, during the sub-period 1991 to 1998, all sixteen strategies earn significant positive returns, ranging between 0.98 and 1.96 percent (with a mean of 1.54 percent); during the sub-period 1998 to 2006, eleven strategies earn significant positive returns, ranging between -0.51 and 1.86 percent (with a mean of 0.80 percent). In Germany, during the sub-period 1991 to 1998, fifteen strategies earn significant positive returns, ranging between 0.64 and 1.68 percent (with a mean of 1.11 percent); during the subperiod 1998 to 2006, eleven strategies earn significant positive returns, ranging between 0.08 and 1.55 per cent (with a mean of 0.86 per cent). In both markets, the portfolios earn a higher average profit in the first sub-period than in the second sub-period.

The markets of Japan and China exhibit a different sub-period pattern from those of the United Kingdom and Germany. In Japan, during the sub-period 1991 to 1998, all sixteen strategies earn significant negative returns, ranging between -1.60 and -0.38 percent (with a mean of -0.81 percent); the negative returns disappear for most of the strategies during the sub-period 1999 to 2006. In China, during the sub-period 1995 to 2000, only one strategy earns significant negative returns; however, during the sub-period 2001 to 2006, fifteen strategies show positive momentum profits, ranging between 0.58 and 2.14 percent (with a mean of 1.26 percent).

We test for the joint significance of these strategies within each time period for each country. There is strong evidence that the momentum is profitable in all time periods for the United King and Germany, and 2001-2006 sub-period for China: the chi-square statistics for each have a $p$-value of zero. Negative significant returns are found for the 1991-1998 sub-period for Japan,

\footnotetext{
${ }^{2}$ We include the sub-periods to investigate the robustness of the momentum profits in the sample markets.
} 
whose chi-square statistics have a zero $p$-value. Hence, the most convincing evidence in Table 2 is consequently in favor of momentum strategy in the United Kingdom, Germany, and China. The contrary strategy works in Japan.

\subsection{Profits of Weighted Relative Strength Strategy (WRSS)}

This subsection examines the profits of weighted Relative Strength Strategy. As in Section 2.2, each test period is divided into $J$-month formation period (from time $t-2$ to $t$-1) and $k$-month holding period (from time $t-1$ to $t$ ). Following Conrad and Kaul (1998), the weight of each security in the trading portfolio in the holding period is determined by the relative performance of the security to the equal-weighted market portfolio in the formation period. Specifically,

$$
w_{i, t-1}(k)=+\frac{1}{N}\left[R_{i, t-1}(J)-R_{m, t-1}(J)\right]
$$

where $w_{i, t-1}$ is the fraction of the trading strategy portfolio devoted to security $i$ in holding period, $R_{i, t-1}$ is the return of security $i$ in the formation period, and $R_{m, t-1}$ is the equal-weighted market portfolio in the formation period. $N$ is the number of securities in the portfolio at time $t-1$, and $i=1, \ldots, N$.

The plus sign in Eq. (1) emphasizes that we will implement a moment strategy, i.e., going long in a security if it outperforms the equal-weighted market portfolio and going short in a security if it underperforms the market portfolio.

By construction, the portfolio is an arbitrage portfolio since the weights of securities sum to zero. And the total investment position (long or short) is given by:

$$
I_{t}=\frac{1}{2} \sum_{i=1}^{N}\left|w_{i, t-1}(k)\right|
$$

The profit in the holding period from the strategy is:

$$
\pi_{t}=\sum_{i=1}^{N} w_{i, t-1}(k) R_{i, t}(k)
$$

Table 3 reports the average monthly returns over different formation/holding periods in each country, with Panels A, B, C, and D presenting the results for the United Kingdom, Germany, Japan, and China, respectively. For each market, the time periods considered are the same as those in the case of RSS. For each strategy, the table lists the returns of the strategy and associated $t$-statistics. For instance, as Panel A shows, a 3-month/3-month WRSS strategy in the United Kingdom earns an average return of 0.081 percent per month, which is significant at the 5 percent level of significance, with a $t$-statistic of 1.94 .

Over the sixteen entire period strategies in each market, significantly positive excess returns are obtain at the 5 percent level for fifteen strategies in the United Kingdom, sixteen in Germany, zero in Japan, and zero in China. Significant negative excess returns at the 5 percent level are only seen for two strategies in Japan. Specifically, the average returns over different formation/holding periods range from 0.044 to 0.306 percent per month in the United Kingdom (with a mean of 0.140 percent), from 0.078 to 0.340 percent in Germany (with a mean of 0.211 percent), from -0.080 to 0.002 percent in Japan (with a mean of -0.030 percent), and from 0.033 to 0.040 percent in China (with a mean of 0.012 percent). 


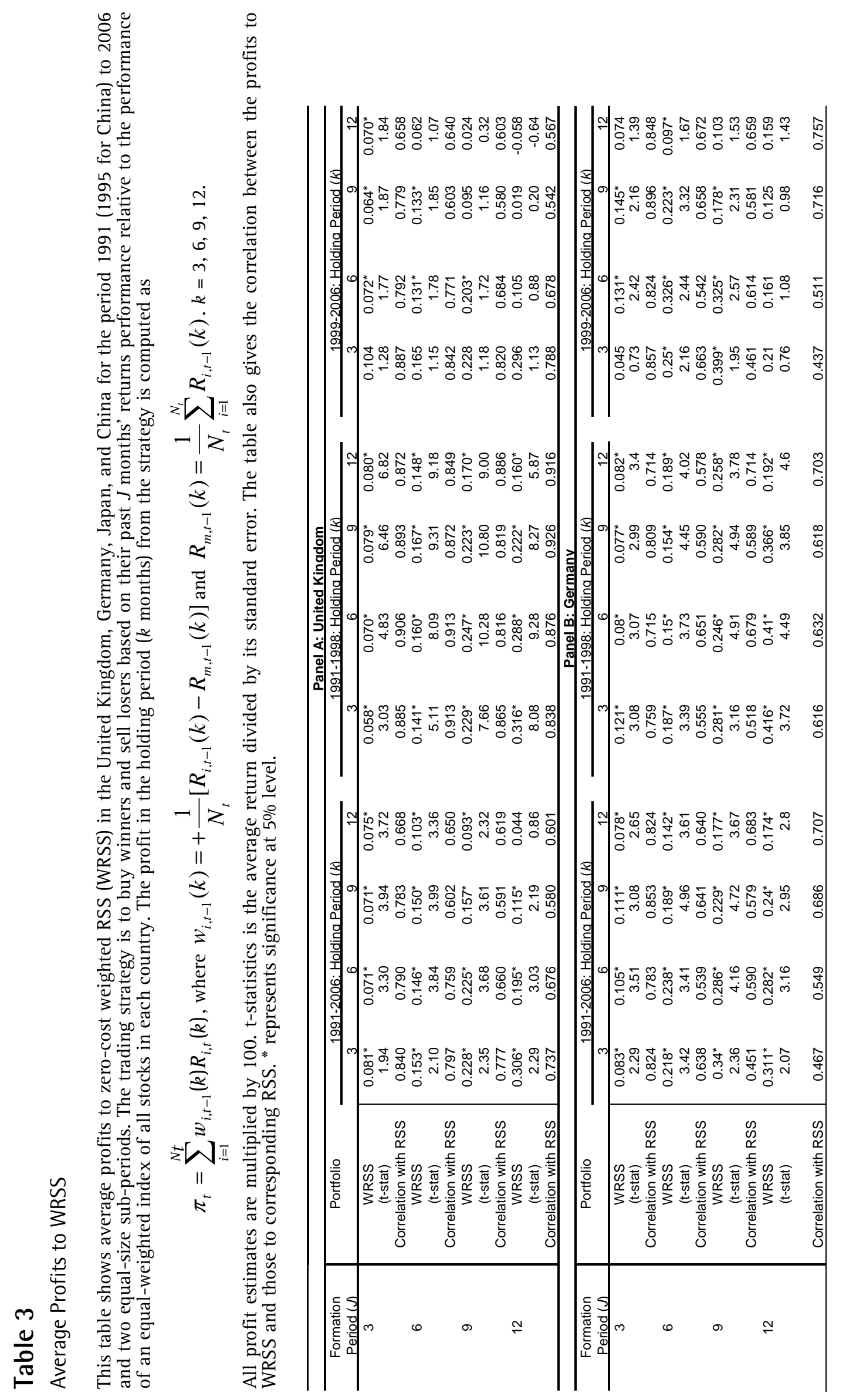




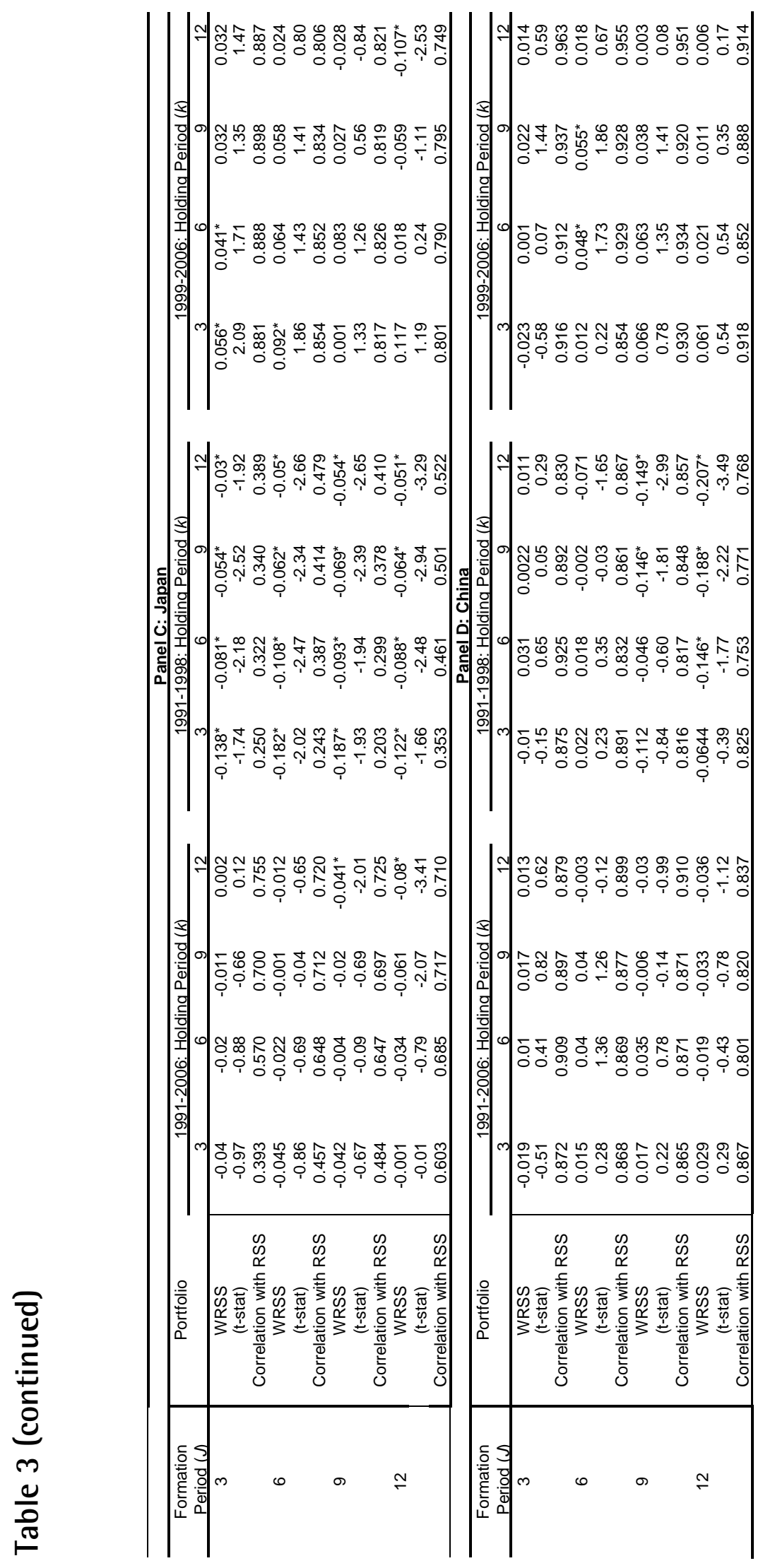


For the sub-periods, the United Kingdom and Germany document portfolio returns at a comparable scale to those of the entire sample period, with a majority of the strategies earning significant positive returns. However, the strategies earn significantly negative returns for the sub-period 1991-1998 in Japan. Insignificant profits are reported for a majority of the strategies for sub-period 1999-2006 in Japan and both sub-periods in China.

In sum, the most convincing evidence in Table 3 is in favor of momentum strategy in the United Kingdom and Germany in all periods. The contrary strategy dominates in Japan during the sub-period 1991-1998.

Table 3 also lists the correlation between the profits of the WRSS over different formation/holding combinations and those of the corresponding RSS. Jegadeesh and Titman (1993) report a correlation as high as 0.95 for the 6-month/6-month strategy in the United States. Our paper reveals that the correlations between the two methods varies over different formation/holding periods in each country, ranging from 0.542 to 0.926 for the United Kingdom, from 0.437 to 0.896 for Germany, from 0.203 to 0.898 for Japan, and from 0.763 to 0.963 for China. With these numbers, we tend to believe that the returns of RSS and WRSS are evidently positively correlated.

Next, we use the RSS to analyze the risk factors, calendar effect, and other characteristics of the momentum, and the WRSS to decompose the profits of the momentum strategies. Unless otherwise indicated, we focus, in the remainder of the paper, on the portfolios formed on the basis of the previous six months' return and held for six months, i.e., 6-month/6-month strategy. On one hand, it is consistent with the literature; on the other hand, the results of 6-month/6-month strategy are representative for other strategies in each period across our sample.

\section{Characteristics of Momentum Strategies (with RSS)}

\subsection{Risk-Adjusted Returns}

This subsection explores the relationship between the returns of momentum portfolios and Fama-French risk factors: market factor (the value-weighted index minus the risk-free rate), size factor (SMB, small stocks minus big stocks), and book-to-market factor (HML, high minus low book-to-market stocks).

In each market, we regress the monthly returns of the momentum strategy in excess of the riskfree interest rate, $R_{R S S, t}-r_{f, t}$, on the excess return of the Morgan Stanley Capital International index of each sample country over the risk-free interest rate, $R_{M, t}-r_{f, t}$, and the Fama-French SMB and HML factors over the sample period.

$$
R_{R S S, t}-r_{f, t}=\alpha+\beta_{m}\left(R_{M, t}-r_{f, t}\right)+\beta_{s m b} S M B_{t}+\beta_{h m l} H M L_{t}+e_{t}
$$




\section{Table 4}

Risk Adjusted Excess Returns of Momentum Portfolios

This table provides the results from regression, in each market, the monthly returns of the 6-month/6-month momentum strategy in excess of the risk-free interest rate on Fama-French three-factors: $\left(R_{M}-r_{f}\right), R_{S M B}$, and $R_{H M L}$ over the sample period:

$$
R_{R S S, t}-r_{f, t}=\alpha+\beta_{m}\left(R_{M, t}-r_{f, t}\right)+\beta_{s m b} R_{S M B, t}+\beta_{h m l} R_{H M L, t}+e_{t}
$$

$R^{2}$ is the coefficient of determination adjusted for degrees of freedom; $t(\cdot)$ is the related coefficient divided by its standard error.

\begin{tabular}{lccccccccc}
\hline \multicolumn{1}{c}{$\alpha$} & \multicolumn{1}{c}{$\boldsymbol{t}(\alpha)$} & $\beta_{m}$ & $t\left(\beta_{m}\right)$ & $\beta_{\text {smb }}$ & $t\left(\beta_{\text {smb }}\right)$ & $\beta_{h m l}$ & $t\left(\beta_{h m l}\right)$ & $R^{2}$ \\
\hline $\begin{array}{l}\text { United } \\
\text { Kingdom }\end{array}$ & & & & & & & & & \\
$1991-2006$ & $0.0134^{*}$ & 5.86 & -0.047 & -0.85 & $-0.0755^{*}$ & -1.97 & $-0.2702^{*}$ & -4.16 & 0.1 \\
$1991-1998$ & $0.0121^{*}$ & 5.11 & -0.0122 & -0.21 & -0.0419 & -0.77 & $-0.2264^{*}$ & -2.95 & 0.09 \\
$1999-2006$ & $0.0153^{*}$ & 3.57 & -0.0645 & -0.65 & -0.098 & -1.69 & $-0.3169^{*}$ & -2.93 & 0.11 \\
\hline Germany & & & & & & & & & \\
$1991-2006$ & $0.0097^{*}$ & 3.47 & -0.0494 & -0.95 & -0.0362 & -0.6 & $-0.0913^{*}$ & -2.04 & 0.02 \\
$1991-1998$ & 0.0040 & 1.48 & $0.2251^{*}$ & 4.07 & $0.1928^{*}$ & 3.19 & -0.0016 & -0.04 & 0.19 \\
$1999-2006$ & $0.0184^{*}$ & 4.08 & $-0.3406^{*}$ & -4.28 & $-0.3223^{*}$ & -3.42 & $-0.257^{*}$ & -3.51 & 0.2 \\
\hline Japan & & & & & & & & & \\
$1991-2006$ & $-0.0050^{*}$ & -2.59 & -0.0519 & -1.4 & $-0.1601^{*}$ & -3.42 & $-0.3715^{*}$ & -6.57 & 0.22 \\
$1991-1998$ & $-0.0136^{*}$ & -5.23 & -0.0512 & -1.13 & $-0.2472^{*}$ & -3.72 & -0.1840 & -1.6 & 0.2 \\
\hline China & & & & & & & & & \\
$1995-2006$ & $0.0075^{*}$ & 2.3 & -0.0174 & -0.46 & 0.0586 & 1.15 & 0.03 & 0.86 & 0.02 \\
$2001-2006$ & $0.0140^{*}$ & 3.62 & -0.0086 & -0.17 & 0.1271 & 1.62 & 0.1812 & 1.78 & 0.09 \\
\hline
\end{tabular}

Table 4 reports the results of the regression for periods that, on average, earn significant positive or negative returns. As is shown in column 4, nearly all the market factor coefficients $\left(\beta_{m}\right)$ are negative, indicating that the losers are somewhat more sensitive to the market risk factor than the winners. A closer look at column 5 shows that only two coefficients for the subperiods in Germany are significantly different from zero, meaning that market betas for winners and losers are virtually equal. Columns 6-9 reveal the effect of the size factor coefficients $\left(\beta_{\text {smb }}\right)$ and book-to-market factor coefficients $\left(\beta_{h m l}\right)$. The signs are mostly negative and the significant levels are mixed. This indicates that the losers are riskier than the winners because they are relatively more sensitive to all three Fama-French factors.

The second column of Table 4 reports the alpha $(\alpha)$ of the various momentum portfolios estimated by regressing the monthly momentum returns on the Fama-French factors. The alphas for these risk-adjusted portfolios are about the same as the raw returns, with the only exception of Germany during the 1991-1998 sub-period. The last column of the table presents the $R$-square of each regression, ranging from 0.02 to 0.22 .

In sum, the Fama-French three-factor model cannot explain the profits of the momentum strategies in most of the cases. 


\subsection{Seasonality Effect}

Jegadeesh and Titman $(1993,2001)$ find an interesting seasonality in momentum profits in the United States. They document that the Winners outperform the Losers in all months except January, when the Losers outperform the Winners. Grundy and Martin (2001) also report similar results in the U.S., where the momentum portfolio earns significantly negative returns in Januaries and significantly positive returns in months other than January. However, we think this seasonality might be simply a statistical fluke. With sample markets additional to the United States, we can examine the performance of the strategy in January and non-January months to see whether the January effect applies in these markets.

Table 5 reports the average monthly momentum portfolio returns and the percentage of months with positive returns for January as well as non-January months in each market. Column 4 in the table is the associated $t$-statistics. Different from earlier findings in the United States market, the momentum profits in January show significant positive returns in the United Kingdom, Germany, and China; not different from those in non-January months in each market. The only exception is found in Japan, in which the January returns are insignificantly different from zero.

\section{Table 5}

Momentum Returns in January and Outside January

This table reports the average monthly momentum portfolio returns, associated t-statistic, and the percentage of positive returns for January as well as non-January months in each market. The momentum portfolios are formed based on previous six-month returns and held for six months. The table also reports the difference between the January monthly returns and the non-January monthly returns.

\begin{tabular}{ccccc}
\hline Country & Month & Average & t-statistic & Percent Positive \\
\cline { 2 - 5 } United & Overall & $0.0160^{*}$ & 7.15 & 77.6 \\
Kingdom & Jan & $0.0272^{*}$ & 4.50 & 87.5 \\
& Others & $0.0150^{*}$ & 6.33 & 76.7 \\
& Jan-Others & 0.0122 & 1.52 & \\
& & & & \\
Germany & Overall & $0.0118^{*}$ & 4.47 & 67.7 \\
& Jan & $0.0242^{*}$ & 3.84 & 87.5 \\
& Others & $0.0107^{*}$ & 3.79 & 65.9 \\
& Jan-Others & 0.0135 & 1.42 & \\
\multirow{4}{*}{ Japan } & & & & 46.4 \\
& Overall & $-0.0051^{*}$ & -2.42 & 43.8 \\
& Jan & 0.0018 & 0.37 & 46.6 \\
& Others & $-0.0058^{*}$ & -2.54 & \\
& Jan-Others & 0.0076 & 0.98 & 59.1 \\
China & & & & 72.7 \\
& Overall & $0.0111^{*}$ & 3.44 & 57.9 \\
& Jan & $0.0124^{*}$ & 1.99 & \\
& Others & $0.0109^{*}$ & 3.15 & \\
& Jan-Others & 0.0015 & 0.13 & \\
\hline
\end{tabular}


Table 5 also reports the test of the difference between the average monthly January returns and the average monthly non-January returns. Not surprisingly, the difference is insignificant in all markets.

\subsection{Post-holding Period Cumulative Profits to the Momentum Strategy}

In this subsection we examine the results of momentum portfolios over various time horizons $(K)$ to check the behavior of the momentum returns over time. This provides information on the duration of the continuation effect and the extent to which it is permanent.

Table 6 gives the monthly average momentum portfolio returns and associated $t$-statistics in the first five years after portfolio formation based on previous six-month returns. For Japan, the average returns have been persistently negative since formation. On the contrary, for the United Kingdom, Germany, and China, the returns are nearly uniformly positive in the first two years, after which they turn negative. It is interesting to note that the returns over the last 12 months turn positive in Germany, although most of them are insignificant or marginally significant. In sum, this suggests that part of the continuation effect in these three countries may be temporary and is reversed in the third year after portfolio formation. These results are very similar to Jegadeesh and Titman (1993) for the United States, except that the turning point here is in about two years instead of one year in the United States.

\section{Table 6}

Post-holding Period Returns

This table reports the average monthly momentum portfolio returns and associated t-statistic over a 60-month post-formation period in each market. The momentum portfolios are formed based on previous six-month returns. The number in bold means significantly different from zero at 5\% level.

\begin{tabular}{|c|c|c|c|c|c|c|c|c|}
\hline \multirow[b]{2}{*}{ Month } & \multicolumn{2}{|c|}{ United Kingdom } & \multicolumn{2}{|c|}{ Germany } & \multicolumn{2}{|c|}{ Japan } & \multicolumn{2}{|c|}{ China } \\
\hline & Average & t-statistic & Average & t-statistic & Average & t-statistic & Average & t-statistic \\
\hline 1 & 0.0110 & 2.19 & 0.0001 & 0.01 & -0.0125 & -2.16 & 0.0032 & 0.33 \\
\hline 2 & 0.0154 & 3.96 & 0.0078 & 1.77 & -0.0068 & -1.80 & 0.0067 & 1.02 \\
\hline 3 & 0.0175 & 5.15 & 0.0114 & 3.47 & -0.0052 & -1.83 & 0.0093 & 1.78 \\
\hline 4 & 0.0174 & 5.77 & 0.0124 & 4.38 & -0.0050 & -2.08 & 0.0105 & 2.53 \\
\hline 5 & 0.0166 & 6.32 & 0.0121 & 4.50 & -0.0053 & -2.37 & 0.0102 & 2.87 \\
\hline 6 & 0.0160 & 7.15 & 0.0118 & 4.47 & -0.0051 & -2.42 & 0.0110 & 3.44 \\
\hline 7 & 0.0148 & 7.18 & 0.0108 & 3.81 & -0.0042 & -2.07 & 0.0114 & 3.76 \\
\hline 8 & 0.0140 & 6.98 & 0.0118 & 4.03 & -0.0033 & -1.73 & 0.0104 & 3.61 \\
\hline 9 & 0.0134 & 6.84 & 0.0115 & 3.87 & -0.0028 & -1.54 & 0.0097 & 3.49 \\
\hline 10 & 0.0125 & 6.59 & 0.0096 & 3.58 & -0.0024 & -1.40 & 0.0078 & 2.84 \\
\hline 11 & 0.0115 & 5.99 & 0.0077 & 2.70 & -0.0023 & -1.43 & 0.0063 & 2.43 \\
\hline 12 & 0.0103 & 5.38 & 0.0053 & 1.34 & -0.0027 & -1.77 & 0.0041 & 1.62 \\
\hline 13 & 0.0090 & 4.77 & 0.0066 & 2.04 & -0.0035 & -2.43 & 0.0022 & 0.81 \\
\hline 14 & 0.0079 & 4.45 & 0.0077 & 2.19 & -0.0042 & -3.00 & 0.0010 & 0.36 \\
\hline 15 & 0.0070 & 3.84 & 0.0079 & 2.31 & -0.0051 & -3.40 & 0.0001 & 0.05 \\
\hline 16 & 0.0058 & 3.25 & 0.0065 & 2.01 & -0.0057 & -3.74 & 0.0001 & 0.02 \\
\hline 17 & 0.0050 & 2.73 & 0.0034 & 0.93 & -0.0060 & -4.01 & 0.0007 & 0.28 \\
\hline 18 & 0.0040 & 2.36 & 0.0035 & 1.02 & -0.0064 & -4.34 & 0.0020 & 0.83 \\
\hline 19 & 0.0032 & 2.06 & 0.0023 & 0.64 & -0.0064 & -4.60 & 0.0027 & 1.19 \\
\hline 20 & 0.0025 & 1.58 & -0.0007 & -0.19 & -0.0065 & -4.86 & 0.0031 & 1.34 \\
\hline
\end{tabular}




\begin{tabular}{|c|c|c|c|c|c|c|c|c|}
\hline 21 & 0.0019 & 1.22 & -0.0042 & -0.92 & -0.0065 & -5.24 & 0.0033 & 1.40 \\
\hline 22 & 0.0013 & 0.82 & -0.0064 & -1.16 & -0.0064 & -5.47 & 0.0031 & 1.37 \\
\hline 23 & 0.0007 & 0.45 & -0.0081 & -1.49 & -0.0066 & -5.84 & 0.0019 & 0.86 \\
\hline 24 & 0.0001 & 0.04 & -0.0096 & -1.89 & -0.0064 & -5.90 & 0.0005 & 0.21 \\
\hline 25 & -0.0005 & -0.35 & -0.0109 & -2.26 & -0.0066 & -6.04 & -0.0010 & -0.38 \\
\hline 26 & -0.0011 & -0.76 & -0.0103 & -2.34 & -0.0067 & -6.12 & -0.0028 & -0.91 \\
\hline 27 & -0.0018 & -1.26 & -0.0096 & -2.40 & -0.0070 & -6.25 & -0.0037 & -1.20 \\
\hline 28 & -0.0026 & -1.83 & -0.0097 & -2.61 & -0.0070 & -6.40 & -0.0048 & -1.49 \\
\hline 29 & -0.0030 & -2.17 & -0.0088 & -2.54 & -0.0069 & -6.44 & -0.0056 & -1.69 \\
\hline 30 & -0.0031 & -2.29 & -0.0082 & -2.37 & -0.0070 & -6.45 & -0.0063 & -1.92 \\
\hline 31 & -0.0030 & -2.30 & -0.0079 & -2.14 & -0.0068 & -6.38 & -0.0070 & -2.16 \\
\hline 32 & -0.0029 & -2.27 & -0.0073 & -2.01 & -0.0067 & -6.41 & -0.0078 & -2.43 \\
\hline 33 & -0.0029 & -2.29 & -0.0070 & -2.04 & -0.0064 & -6.24 & -0.0084 & -2.58 \\
\hline 34 & -0.0027 & -2.19 & -0.0068 & -2.06 & -0.0061 & -6.08 & -0.0086 & -2.81 \\
\hline 35 & -0.0027 & -2.24 & -0.0078 & -2.29 & -0.0059 & -5.79 & -0.0087 & -3.07 \\
\hline 36 & -0.0025 & -2.11 & -0.0079 & -2.30 & -0.0058 & -5.52 & -0.0091 & -3.32 \\
\hline 37 & -0.0026 & -2.26 & -0.0078 & -2.37 & -0.0056 & -5.47 & -0.0094 & -3.57 \\
\hline 38 & -0.0027 & -2.35 & -0.0079 & -2.41 & -0.0056 & -5.59 & -0.0100 & -3.85 \\
\hline 39 & -0.0028 & -2.41 & -0.0077 & -2.39 & -0.0055 & -5.81 & -0.0106 & -4.04 \\
\hline 40 & -0.0030 & -2.49 & -0.0076 & -2.40 & -0.0055 & -6.21 & -0.0113 & -4.29 \\
\hline 41 & -0.0030 & -2.47 & -0.0066 & -2.22 & -0.0055 & -6.72 & -0.0119 & -4.58 \\
\hline 42 & -0.0032 & -2.58 & -0.0058 & -2.07 & -0.0055 & -7.06 & -0.0122 & -4.71 \\
\hline 43 & -0.0033 & -2.63 & -0.0050 & -1.96 & -0.0054 & -7.19 & -0.0127 & -4.91 \\
\hline 44 & -0.0032 & -2.58 & -0.0042 & -1.75 & -0.0052 & -7.12 & -0.0130 & -5.15 \\
\hline 45 & -0.0030 & -2.49 & -0.0032 & -1.45 & -0.0050 & -6.88 & -0.0133 & -5.36 \\
\hline 46 & -0.0028 & -2.27 & -0.0024 & -1.10 & -0.0048 & -6.58 & -0.0132 & -5.26 \\
\hline 47 & -0.0025 & -2.09 & -0.0011 & -0.56 & -0.0046 & -6.39 & -0.0130 & -5.33 \\
\hline 48 & -0.0024 & -1.90 & -0.0002 & -0.12 & -0.0043 & -6.04 & -0.0125 & -5.37 \\
\hline 49 & -0.0023 & -1.82 & 0.0004 & 0.22 & -0.0040 & -5.82 & -0.0119 & -5.34 \\
\hline 50 & -0.0021 & -1.64 & 0.0008 & 0.41 & -0.0037 & -5.64 & -0.0115 & -5.38 \\
\hline 51 & -0.0021 & -1.66 & 0.0013 & 0.72 & -0.0036 & -5.45 & -0.0111 & -5.36 \\
\hline 52 & -0.0022 & -1.69 & 0.0017 & 0.94 & -0.0034 & -5.35 & -0.0111 & -5.33 \\
\hline 53 & -0.0023 & -1.81 & 0.0023 & 1.28 & -0.0033 & -5.50 & -0.0112 & -5.15 \\
\hline 54 & -0.0024 & -1.90 & 0.0026 & 1.46 & -0.0033 & -5.49 & -0.0116 & -5.06 \\
\hline 55 & -0.0026 & -2.04 & 0.0028 & 1.54 & -0.0032 & -5.56 & -0.0124 & -5.01 \\
\hline 56 & -0.0027 & -2.13 & 0.0033 & 1.91 & -0.0031 & -5.51 & -0.0128 & -5.10 \\
\hline 57 & -0.0026 & -2.02 & 0.0036 & 2.05 & -0.0030 & -5.26 & -0.0131 & -5.21 \\
\hline 58 & -0.0025 & -1.88 & 0.0037 & 1.97 & -0.0028 & -5.01 & -0.0136 & -5.62 \\
\hline 59 & -0.0028 & -2.15 & 0.0040 & 2.17 & -0.0026 & -4.75 & -0.0141 & -6.01 \\
\hline 60 & -0.0028 & -2.16 & 0.0038 & 2.05 & -0.0024 & -4.50 & -0.0140 & -6.00 \\
\hline
\end{tabular}

Figure 1 depicts the evolution of the cumulative momentum profits over an event time of 60month post-formation period. Cumulative momentum profits of the three momentum profitable markets increase monotonically in the first two years until they reach the peaks between 10 and 20 percent. The three markets differ in the magnitude of subsequent return reversals: The United Kingdom shows a moderate reversal and maintains a profit level above 10 percent; profits in Germany fluctuate around zero; and China reveals the most dramatic reversal, with the cumulative profits declining to -20 percent. These results are consistent with the behavioral models that predict that momentum profits will be reversed eventually. In other words, $H 1$ is supported. 


\section{Figure 1}

Cumulative Momentum Profits

This figure presents cumulative momentum portfolio returns of RSS over a 60-month postformation period. The sample stocks cover over 95 percent of the market capitalization in each country. The momentum portfolios are formed based on previous six-month returns.

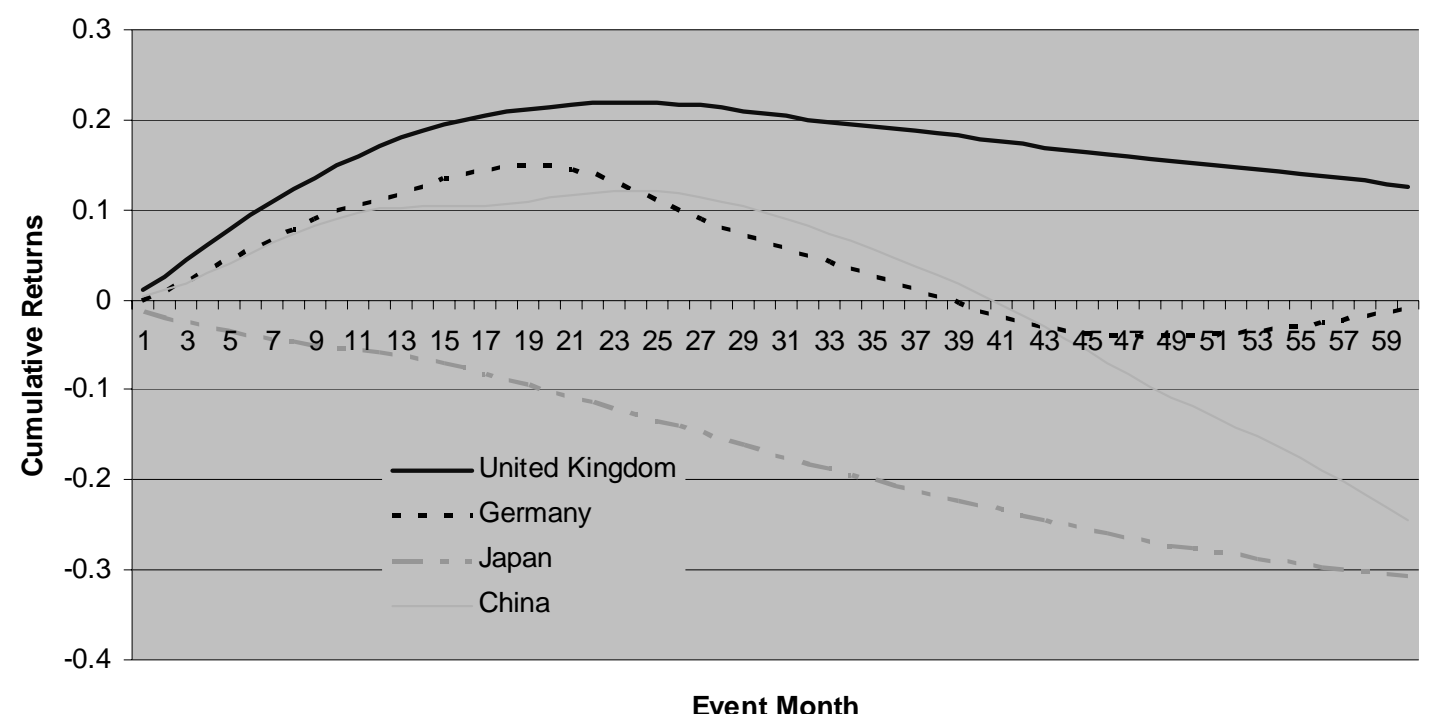

\subsection{Correlation: Are There Common Components Across the Markets?}

Gouwenhorst (1998) checks the correlation between European markets and the United States market and concludes that momentum returns have common components across different markets. In this paper, we test whether these common components persist and whether they provide "independent" evidence about the profitability of momentum strategies in each market.

\section{Table 7}

Correlation of Momentum Profits (6-month/6-month) Between Sample Markets and the United States

\begin{tabular}{|c|c|c|c|c|c|}
\hline & $\begin{array}{l}\text { United } \\
\text { Kingdom }\end{array}$ & Germany & Japan & China & $\begin{array}{l}\text { United } \\
\text { States }\end{array}$ \\
\hline United Kingdom & 1 & & & & \\
\hline Germany & 0.475 & 1 & & & \\
\hline Japan & 0.104 & -0.023 & 1 & & \\
\hline China & 0.065 & 0.138 & -0.134 & 1 & \\
\hline United States & 0.085 & 0.049 & 0.081 & -0.029 & 1 \\
\hline
\end{tabular}

Table 7 presents the correlation among the momentum profits of our sample markets and the United States over the entire sample period. ${ }^{3}$ We do not observe clear patterns in the table, since the sample correlations between the countries are mixed in sign, ranging from -0.134 to

\footnotetext{
${ }^{3}$ The momentum profits of the United States market are obtained from the French's webpage.
} 
0.475. Nevertheless, the correlation between the United Kingdom and Germany reaches as high as 0.475 , indicating strong positive dependence across the two markets.

A regression of the $R_{R S S, t \mid U . K \text {. }}$ on $R_{R S S, t \mid G e r m a n y}$ has been run to evaluate the profitability of the United Kingdom strategy conditional on the Germany experience:

$$
R_{R S S, t \mid U . K .}=0.0115+0.381 R_{R S S, t \mid \text { Germany }}+e_{t}, \quad \mathrm{R}^{2}=0.203,
$$

where $t$-statistics are given in parentheses. Assuming joint normality, the intercept of the regression measures the average return of the independent part of the United Kingdom momentum portfolio to the Germany momentum returns. Conditioning on Germany reduces the average returns of the United Kingdom momentum profits from 1.60 to 1.15 percent per month, but the high $t$-statistic of the intercept implies profitability of the United Kingdom momentum strategies that is independent of a common component with Germany. In this sense, the United Kingdom and Germany provide evidence of momentum strategies independent from each other.

\subsection{Transaction Costs}

Transaction costs of implementing the momentum strategies may cancel out all or part of the momentum profits documented in our sample markets. Transaction costs for a single round-trip in all these markets are typically below one percent, implying round-trip transaction costs below two percent. Figure 1 shows that the absolute value of cumulative momentum profits significantly exceeds a two percent transaction cost for holding periods between 3 and 36 months.

Besides, the turnover of positions in the strategies is far from 100 percent per month since any two neighboring formation periods share $K-1$ months in common. Thus, Winner/Loser stocks over a $K$ month formation period are likely to still qualify as Winner/Loser for the next formation period. Grundy and Martin (2001) report an average 40 percent of turnover for both the winner and the loser portfolios. Given this fact, the momentum profits obtained in each market remain significantly different from zero after considering the transaction costs.

\section{Decomposition of the Profit Sources (with WRSS)}

In this section, we decompose the profits of WRSS and study the hypothesis developed in Section I, along with some discussions on other aspects of the trading strategies.

To decompose the WRSS profit, we assume that the realized return of stock $i$ is expressed as:

$$
R_{i, t}(k)=\mu_{i, t}(k)+u_{i, t}(k)
$$

where $\mu_{i, t}(k)$ is the unconditional expected return of stock $i$ and $u_{i, t}(k)$ is the unexpected return at time $t$. Then the momentum profits in Eq.(6) can be decomposed into components based on expected and unexpected components of returns as follows:

$$
\begin{aligned}
& E\left[\pi_{t}(k)\right]=-\operatorname{Cov}\left(R_{m, t}(k), R_{m, t-1}(J)\right)+\frac{1}{N} \sum_{i=1}^{N} \operatorname{Cov}\left(R_{i, t}(k), R_{i, t-1}(J)\right)+\frac{1}{N} \sum_{i=1}^{N}\left[\mu_{i, t-1}(k)-\mu_{m, t-1}(J)\right]^{2} \\
& =-C_{1}(k)+O_{1}(k)+\sigma^{2}[\mu(k)] \\
& =P(k)+\sigma^{2}[\mu(k)]
\end{aligned}
$$


where $C_{1}(k)$ is the first-order autocovariance of the returns on the market portfolio, $O_{1}(k)$ is the average of the first-order autocovariances of the $N$ individual stocks in the zero cost portfolio, $\mu_{m, t}(k)=\frac{1}{N} \sum_{i=1}^{N} \mu_{i, t}(k)$, and $\sigma^{2}[\mu(k)]$ is the cross-sectional variance of expected returns. ${ }^{4}$ In calculating the components of the trading portfolio profits, we assume that individual stock returns are mean stationary.

Eq. (7) decomposes the total expected profits into two components: $P(k)$, the time-series predictable components in asset returns, and $\sigma^{2}[\mu(k)]$, the profits generated by cross-sectional variance of the mean returns. The equation indicates that any cross-sectional variation in expected returns contributes positively to momentum profits. Since realized past returns are positively correlated with expected returns, if a large part of realized returns is due to expected returns, past Winners (Losers) will on average continue to earn higher (lower) than average returns in the future.

Following Conrad and Kaul (1998), we assume that the serial covariances and the crosssectional variances of mean returns of individual stocks are time dependent. Then, $-C_{1}(k)$, $O_{1}(k)$, and $\sigma^{2}[\mu(k)]$ are estimated as:

where

$$
-\hat{C}_{1}(k)=-\frac{1}{T(k)-1} \sum_{t(k)=2}^{T(k)} C_{1, t}(k)
$$

$$
\begin{gathered}
C_{1, t}(k)=R_{m, t}(k) R_{m, t-1}(J)+\hat{\mu}_{m, t-1}^{2}(k)+\frac{1}{N^{2}} \sum_{i=1}^{N}\left[R_{i, t}(k) R_{i, t-1}(J)-\hat{\mu}_{i, t-1}^{2}(J)\right] \\
\hat{O}_{1}(k)=\frac{1}{T(k)-1} \sum_{t(k)=2}^{T(k)} O_{1, t}(k)
\end{gathered}
$$

where

$$
O_{1, t}(k)=\frac{N-1}{N^{2}-1} \sum_{i=1}^{N}\left[R_{i, t}(k) R_{i, t-1}(J)-\hat{\mu}_{i, t-1}^{2}(J)\right]
$$

and

$$
\hat{\sigma}^{2}[\mu(k)]=\frac{1}{T(k)-1} \sum_{t(k)=2}^{T(k)} \sigma_{t}^{2}(k)
$$

where

$$
\sigma_{t}^{2}(k)=\frac{1}{N} \sum_{i=1}^{N}\left[\hat{\mu}_{i, t-1}(J)-\hat{\mu}_{m, t-1}(J)\right]^{2}
$$

$T(k)$ is the total number of overlapping returns in the sample period for a trading strategy of holding period $k . \hat{\mu}_{m, t-1}(J), \hat{\mu}_{i, t-1}(J)$ are the estimated expected returns of stock $i$, and market portfolio at time $t-1 . \hat{\mu}_{i, t-1}$ is estimated through average realized returns of each stock:

$$
\hat{\mu}_{i, t-1}=\frac{1}{T_{i}} \sum_{t=1}^{T_{i}} R_{i, t}
$$

\footnotetext{
${ }^{4}$ Lo and MacKinlay (1990) originally propose this decomposition. Jegadeesh and Titman (1995) and Conrad and Kaul (1998) have further treatment of this decomposition and its economic interpretation.
} 
where $T_{i}$ is the number of observations available for stock $i$. Then,

$$
\hat{\mu}_{m, t-1}(k)=\frac{1}{N} \sum_{i=1}^{N} \hat{\mu}_{i, t-1}
$$

Table 8 presents the results of the contribution of time-series predictability and cross-sectional variation of stock returns over different holdings $k$ for the entire sample period of each market, where $k$ ranges from 3 to 12 months. For brevity, we only list strategies for which the length of the formation period $J$ and the future holding period $k$ are identical. Their results are representative for other strategies with different formation and holding periods.

For each panel, columns 2-4 report $\hat{E}\left[\pi_{t}(k)\right], \hat{P}(k)$, and $\hat{\sigma}^{2}[\mu(k)]$. To facilitate evaluation of the relative importance of the profit sources, the percentage contributions of $\hat{P}(k)$ and $\hat{\sigma}^{2}[\mu(k)]$ to the total profits, $\hat{E}\left[\pi_{t}(k)\right]$, are reported in column 5 and column 6 , respectively.

There are several notable findings in Table 8. First, is $\hat{\sigma}^{2}[\mu(k)]$ significant in all cases, given the fact that $\sigma_{t}^{2}(k)$ is the cross-sectional variance of $\hat{\mu}_{i, t-1}$. For the United Kingdom and Germany, $\hat{P}(k)$ is positive with the same significant level as $\hat{E}\left[\pi_{t}(k)\right]$ in most cases; while for Japan and China, $\hat{P}(k)$ is negative but insignificantly different from zero. Second, in the United Kingdom, Germany, and Japan, the absolute value of $\hat{P}(k)$ shows an upward trend from 3 months to 9, and then turns downward at 12 months. The magnitude of $\hat{P}(k)$ in China and $\hat{\sigma}^{2}[\mu(k)]$ in all markets increases monotonically with time. The percentage contribution of $\hat{P}(k)$ dominates that of $\hat{\sigma}^{2}[\mu(k)]$ in nearly all strategies.

\section{Table 8}

The Decomposition of Average Profits to WRSS

This table reports the decomposition of average profits to trading strategies and associated $t$-statistics (with identical formation and holding period) in each market during its entire sample period. The decomposition is given by $\hat{E}\left[\pi_{t}(k)\right]=\hat{P}(k)+\hat{\sigma}^{2}[\mu(k)]$, where $\hat{P}(k)$ and $\hat{\sigma}^{2}[\mu(k)]$ represent the time-series and cross-sectional predictable parts, respectively. All profit estimates are multiplied by $100 .{ }^{*}$ and + denote significance at $5 \%$ and $10 \%$, respectively.

\begin{tabular}{|c|c|c|c|c|c|}
\hline & $\hat{E}\left[\pi_{t}(k)\right]$ & $\hat{P}(k)$ & $\hat{\sigma}^{2}[\mu(k)]$ & $\% \hat{P}(k)$ & $\% \hat{\sigma}^{2}[\mu(k)$ \\
\hline \multicolumn{6}{|c|}{ Panel A: United Kingdom } \\
\hline $\begin{array}{l}3 \text { months } \\
\text { (t-stat) } \\
6 \text { months } \\
\text { (t-stat) } \\
9 \text { months } \\
\text { (t-stat) } \\
12 \text { months } \\
\text { (t-stat) }\end{array}$ & $\begin{array}{l}0.24^{\star} \\
1.94 \\
0.87^{\star} \\
3.84 \\
1.41^{\star} \\
3.61 \\
0.52 \\
0.86 \\
\end{array}$ & $\begin{array}{l}0.17^{\dagger} \\
1.34 \\
0.72^{\star} \\
3.15 \\
1.15^{\star} \\
2.94 \\
0.11 \\
0.18 \\
\end{array}$ & $\begin{array}{l}0.07^{\star} \\
16.61 \\
0.16^{\star} \\
17.71 \\
0.26^{\star} \\
18.69 \\
0.41^{*} \\
20.21 \\
\end{array}$ & $\begin{array}{l}69.23 \\
82.20 \\
81.77 \\
21.06\end{array}$ & $\begin{array}{l}30.77 \\
17.80 \\
18.23 \\
78.93\end{array}$ \\
\hline \multicolumn{6}{|c|}{ Panel B: Germany } \\
\hline $\begin{array}{l}3 \text { months } \\
\text { (t-stat) } \\
6 \text { months } \\
\text { (t-stat) } \\
9 \text { months } \\
\text { (t-stat) } \\
12 \text { months } \\
\text { (t-stat) }\end{array}$ & $\begin{array}{l}0.25^{\star} \\
2.29 \\
1.43^{\star} \\
3.41 \\
2.06^{\star} \\
4.72 \\
2.09^{\star} \\
2.80\end{array}$ & $\begin{array}{l}0.17^{\dagger} \\
1.52 \\
1.22^{\star} \\
2.90 \\
1.56^{\star} \\
3.55 \\
1.03^{\star} \\
1.87\end{array}$ & $\begin{array}{l}0.08^{*} \\
18.87 \\
0.21^{*} \\
24.44 \\
0.50^{\star} \\
35.07 \\
1.06^{\star} \\
35.29\end{array}$ & $\begin{array}{l}67.09 \\
85.10 \\
75.79\end{array}$ & $\begin{array}{l}32.91 \\
14.90 \\
24.21 \\
50.67\end{array}$ \\
\hline
\end{tabular}




\begin{tabular}{llllll}
\hline Panel C: Japan & & & & & \\
\hline 3 months & -0.12 & $-0.21^{\dagger}$ & $0.09^{\star}$ & 171.40 & -71.41 \\
(t-stat) & -0.97 & -1.66 & 65.71 & & \\
6 months & -0.13 & -0.24 & $0.11^{*}$ & 181.73 & -81.73 \\
(t-stat) & -0.69 & -1.26 & 28.46 & & \\
9 months & -0.18 & -0.35 & 0.17 & 196.49 & -96.48 \\
(t-stat) & -0.69 & $-1.36^{\dagger}$ & $21.55^{\star}$ & & \\
12 months & $-0.97^{\star}$ & $-1.22^{*}$ & 0.26 & 126.64 & -26.64 \\
(t-stat) & -3.41 & -4.30 & 18.06 & & \\
\hline Panel D: China & & & & & \\
\hline 3 months & -0.06 & -0.10 & $0.04^{*}$ & 168.16 & -68.17 \\
(t-stat) & -0.51 & -0.86 & 26.83 & & \\
6 months & $0.24+$ & 0.15 & $0.08^{*}$ & 64.45 & 35.55 \\
(t-stat) & 1.36 & 0.88 & 27.94 & & \\
9 months & -0.05 & -0.19 & $0.13^{*}$ & 362.43 & -262.43 \\
(t-stat) & -0.14 & -0.52 & 33.14 & & \\
12 months & -0.44 & -0.63 & $0.20^{*}$ & 145.04 & -45.05 \\
(t-stat) & -1.12 & $-1.63+$ & 38.62 & & \\
\hline
\end{tabular}

The results are revealing in two ways. First, the expected profits are highly predictable for most of the trading strategies from the time-series components, since $\hat{P}(k)$ contributes more of the profits than $\hat{\sigma}^{2}[\mu(k)]$ does. This finding is different from the United States market results by Conrad and Kaul (1998). Second, the results do not support the random walk hypothesis. Although the magnitude of $\hat{\sigma}^{2}[\mu(k)]$ does increase with the trading horizon, the magnitude of the increase is much smaller than the random walk hypothesis indicates. In sum, these results reveal market inefficiencies.

\section{Conclusion}

This paper documents returns of momentum strategies in four sample markets during the period 1991 to 2006. Following the framework developed by Jegadeesh and Titman (1993) and Conrad and Kaul (1998), we measure the momentum profits of RSS and WRSS, obtaining highly correlated results. It turns out that the past Winners outperformed the past Losers for nearly all periods in the United Kingdom, Germany, and most of the periods in China. In Japan, we document negative average returns with the momentum portfolios. Further tests show that the momentum returns cannot be explained by risk models such as the Fama-French three-factor model. Different from the United States market, we do not observe the January effect in our sample markets. The concavity of the cumulative momentum profits over various holding periods show that the behavioral models are supported. Besides, we check the correlation between the sample markets and find only a significant correlation between the United Kingdom and Germany. Furthermore, transaction costs do not rule out the profitability of the momentum strategies for a majority of the holding periods.

We decompose the expected profits of the momentum strategies into two different sources: time-series profitable component and cross-sectional variance of mean returns of individual securities. For all the markets, we find that the expected profits are highly predictable for most of the trading strategies from the time-series components. In addition, the cross-sectional variance of mean returns of individual securities increases with the trading horizon, but the magnitude of the increase is much smaller than the random walk hypothesis predicts. These results cast doubts on market efficiencies. 
Some questions unanswered in the paper point the direction for future research. Are there other risk factors that can help explain the momentum profits? Does the correlation between Germany and the United Kingdom reflect a priced momentum factor that is common across certain markets, say European Union members? Why does Japan appear as an exception? ${ }^{5}$ In decomposing the total momentum profits, we assume that the mean returns of individual securities are constant during the periods in which the trading strategies are implemented. Different specifications of the model for unconditional expected returns could affect our conclusions, and a model of time-varying expected returns could provide deeper insights into the question we are trying to answer. We leave this as a topic for future research.

\footnotetext{
${ }^{5}$ The result itself does not actually come as a big surprise. Japan behaves differently from most other markets in most ways, as reported in the literature. These behaviors may themselves contain the explanation why it is contrarian strategy, and not momentum strategy, that works in Japan in our test.
} 


\section{References}

Barberis, N., A. Shleifer, and R. Vishny (1998), “A Model of Investor Sentiment”, Journal of Financial Economics, 49, pp. 307-343.

Bloomfield, R. and J. Hales (2001), "Predicting the next step of a random walk: Experimental evidence of regime-shifting biases," Cornell University Working Paper.

Chan, K., N. Jegadeesh, and J. Lakonishok (1996), "Momentum strategies," Journal of Finance, 51, pp. 1681-1713.

Chopra, N., J. Lakonishok, and R. Ritter (1992), "Measuring abnormal performance: Do stocks overreact?, Journal of Financial Economics, 31, pp. 235-268.

Chui, A., S. Titman, and K. Wei (2000), "Momentum, ownership structure, and financial crises: An analysis of Asian stock markets," University of Texas at Austin Working Paper.

Conrad, J. and G. Kaul (1998), “An anatomy of trading strategies,” Review of Financial Studies 11, pp. 489-519.

Daniel, K., D. Hirshleifer, and A. Subrahmanyam (1998), "Investor psychology and security market under- and overreactions," Journal of Finance 53, pp. 1839-1886.

DeBondt, W. and R. Thaler (1985), "Does the stock market overreact?" Journal of Finance 40, pp. 793-805.

DeBondt, W. and R. Thaler (1987), "Further evidence on investor overreaction and stock market seasonality”, Journal of Finance 42, pp. 557-581.

Fama, E. (1998), “Does the stock market overreact?” Journal of Financial Economics, 49, pp. 283-306.

Fama, E. and K. French (1996), "Multifactor explanations of asset pricing anomalies," Journal of Finance 51, pp. 55-84.

Grinblatt, M. and B. Han (2001), “The disposition effect and momentum," UCLA Working Paper.

Grinblatt, M., S. Titman, and R. Wermers (1995), "Momentum investment strategies, portfolio performance, and herding: A study of mutual fund behavior," American Economic Review 85, pp. 1088-1105.

Grundy, B. and Martin J. (2001), "Understanding the nature of the risks and the source of the rewards to momentum investing," Review of Financial Studies 14, pp. 29-78.

Hirshleifer, D. and T. Shumway (2003), "Good day sunshine: Stock returns and the weather," Journal of Finance 58, pp. 1009-1032.

Hong, H. and J. Stein (1999), "A unified theory of underreaction, momentum trading and overreaction in asset markets," Journal of Finance 54, pp. 2143-2184.

Jegadeesh, N. and S. Titman (1993), "Returns to buying winners and selling losers: Implications for stock market efficiency”, Journal of Finance 48, pp. 65-91.

Jegadeesh, N. and S. Titman (1995), "Overreaction, delayed reaction and contrarian profits," Review of Financial Studie,s 8,pp. 973-993. 
Jegadeesh, N. and S. Titman (2001), "Profitability of momentum strategies: An evaluation of alternative explanations," Journal of Finance, 56, pp. 699-720.

Lo, A., and A. MacKinlay (1990), "When are contrarian profits due to stock market overreaction?," Review of Financial Studies 3, pp. 175-208.

Rouwenhorst, K. (1998), “International momentum strategies,” Journal of Finance, 53, pp. 267284.

Zarowin, P. (1990), "Size, seasonality, and stock market overreaction," Journal of Financial and Quantitative Analysis, 25, pp. 113-125. 